\title{
TIPO DE FINANCIAMENTO, GRAU DE NOVIDADE DA INOVAÇÃO E TAMANHO DE EMPRESA: UMA ANÁLISE A PARTIR DA PINTEC
}

André Luiz da Silva Teixeira, Renata Guimarães Vieira e Márcia Siqueira Rapini

ÁREA 8: Políticas de Ciência, Tecnologia e Inovação

\begin{abstract}
RESUMO
O presente trabalho analisa quatro instrumentos de financiamento utilizados pelo governo federal no fomento à inovação nas empresas: incentivo fiscal; subvenção econômica; crédito para P\&D\&I; crédito para a compra de máquinas e equipamentos (M\&E). Utilizando uma tabulação especial da PINTEC 20092011, esses instrumentos são relacionados com o grau de novidade da inovação de produto e o porte da empresa. Observa-se que os incentivos fiscais concentram-se em grandes empresas e relacionam-se com inovações novas para o mundo (para as médias empresas), e inovações novas para o país (para as grandes empresas). A subvenção - menos utilizada - é a mais importante para inovações para o mundo, independentemente do porte. O crédito para P\&D\&I concentra-se em médias e grandes empresas, sendo relevante para inovações para o país. Já o crédito para compra de M\&E concentra-se em pequenas empresas e relaciona-se com inovações apenas para a empresa. São necessárias análises setoriais para confirmar essas relações.
\end{abstract}

PALAVRAS-CHAVES: Financiamento à inovação; Porte de empresas; Inovação; PINTEC.

\begin{abstract}
This paper analyses four instruments used by Brazilian federal government to promote the innovation in firms: tax incentives; subvention; credit for R\&D\&I; credit for machinery and equipment acquisition (M\&E). Using a special spreadsheet of Brazilian Innovation Survey (PINTEC, in Portuguese) 2009-2001, these instruments are related with the degree of novelty degree of the product innovation and firm size. This analyses points that tax incentives are concentrated in large firms and for them are related to national innovations, but it is related to world innovation for medium firm. The subvention - least used - is the most important for world innovation regardless the firm size. The credit for R\&D\&I is concentrated in medium or large firms and it is relevant for national innovation. But the credit for M\&E is concentrated in small firms and it is related with innovation only for firms. Sectorial studies are necessary to confirm these connections.
\end{abstract}

KEY WORDS: Finance for Innovation; Size firm; Innovation; PINTEC.

JEL: O31; 038. 


\section{Introdução}

A importância da inovação para o desenvolvimento econômico já é tema extensamente debatido. Este artigo analisa uma das formas pela qual o Estado brasileiro vem buscando dar suporte a tais atividades, que é através de mecanismos de financiamento. O principal motivo para o suporte público às atividades de inovação é o elevado grau de incerteza que não permite cálculos ex-ante da lucratividade esperada. Isto dificulta o envolvimento de agentes privados no financiamento, restando às empresas o uso de recursos próprios (o autofinanciamento) quando possível.

No caso do investimento em pesquisa e desenvolvimento (P\&D), por exemplo, é possível que simplesmente não haja retorno, caso a investigação não resulte em novo produto ou aprimoramento tecnológico, o que dificultaria a concessão de crédito via mercado privado. Mesmo se houver sucesso na pesquisa, os resultados podem ser socializados e compartilhados com outras empresas que não investiram na pesquisa (ainda que o sistema de patentes busque garantir monopólio da tecnologia descoberto por um determinado período inicial).

No caso da adoção de tecnologias que são novas para a empresa, mas já são utilizadas no restante do mercado, há custos associados à absorção de tecnologias tais como treinamento de funcionários ou contratação de mão de obra especializada, que podem restringir o acesso. Além disso, as empresas podem também não ter capacidade de financiar o investimento em novas máquinas e equipamentos com as condições de crédito oferecidas pelo mercado privado.

Dada a relevância do tema, este trabalho procura investigar como se deu o apoio à inovação no Brasil a partir das políticas industriais mais recentes e sua relação com o grau de novidade da inovação de produto implementada. São consideradas neste trabalho três formas principais de apoiar a inovação nas empresas: incentivos fiscais (apoio indireto); subvenções; crédito. Para Araújo (2012), cada uma destas formas uma tem finalidade e público específicos, contribuindo de modo diferenciado para o processo inovativo.

Os incentivos fiscais, segundo as hipóteses defendidas pela literatura, seriam voltados para empresas maiores, que tem mais facilidade de acesso a este tipo de incentivo. Já os créditos supostamente podem favorecer um número maior e mais diverso de empresas que desejam implementar inovações incrementais, enquanto as subvenções seriam destinadas aos projetos que envolvem maior nível de incerteza.

No Brasil, a concessão de crédito para inovação é organizada e concedida principalmente pelo BNDES $^{1}$ e pela FINEP ${ }^{2}$. Segundo Araújo (2012), a Lei de Inovação de 2004 possibilitou maior participação dos recursos da FINEP para empresas, que passaram a contar não só com a concessão de crédito, mas também com o mecanismo de subvenção econômica. Uma empresa pode acessar a FINEP por três formas: financiamento de projetos de cooperação universidade-empresa, concessão de crédito em condições mais favoráveis (atuando em conjunto com os Fundos Setoriais), e a subvenção econômica (que funciona por meio de chamadas públicas abertas para projetos que serão avaliados posteriormente por um conselho).

Sobre a FINEP, observa-se que entre 2010 e 2014, o número de operações de contratação e o valor contratado na modalidade de financiamento reembolsável cresceram substancialmente: o número de operações cresceu de 73 em 2010 para 159 em 2014; já o valor das operações contratadas saiu de R\$ 1.510 milhões em 2010 para R\$ 8.616 milhões em 2014 (RIO DE JANEIRO, 2015). A atuação do BNDES no financiamento ao processo de inovação ganhou folego de novo após 2005, mas foi somente em 2011 com a implementação do "Plano Inova Empresa” em parceria com a FINEP que o mesmo vem conseguindo desembolsar mais recursos para projetos relacionados à inovação: segundo dado do Relatório de Gestão do BNDES, o desembolso para apoiar a inovação foi de R\$ 1.372 milhões em 2010 e R\$ 2.631 milhões em 2011 para R 3.975 milhões em 2014. Especificamente sobre o Plano Inova Empresa, BNDES e FINEP tinham contratado, em 2014, R\$ 17,8 bilhões e R\$ 17,6 bilhões, respectivamente (RIO DE JANEIRO, 2015). Além disso, segundo dados da Pesquisa de Inovação (PINTEC), a proporção de empresas inovadoras que receberam algum tipo de apoio cresceu de 18,8\% em 2003-2005, para 22\% em 2006-2008, chegando a $34 \%$ em $2009-2011^{3}$.

\footnotetext{
${ }^{1}$ BNDES - Banco Nacional de Desenvolvimento Econômico e Social

${ }^{2}$ FINEP - Financiadora de Estudos e Projetos (empresa pública vinculada ao Ministério da Ciência, Tecnologia e Inovação)

${ }^{3}$ Fonte: http://www.pintec.ibge.gov.br/
} 
Nas próximas seções, há uma breve discussão sobre as diferentes formas de financiamento e como elas são oferecidas pelo governo brasileiro. Serão apresentadas algumas hipóteses sobre o perfil de empresas atendidas por cada forma de apoio em termos do porte destas e o tipo de inovação que cada apoio pode estar relacionado. Essas hipóteses serão analisadas na seção 3 a partir de uma tabulação especial da Pesquisa de Inovação (PINTEC) para o período 2009-2011 (IBGE, 2013). Ao final, serão realizadas as considerações e destacadas as limitações do estudo.

\section{Instrumentos de financiamento à inovação no Brasil}

Ainda que a justificativa sobre o financiamento público à inovação seja bastante reconhecida, principalmente após o trabalho recente de Mazzucato (2014), a forma como isto acontece em cada país apresenta especificidades. Há certo consenso sobre a importância da existência de diferentes instrumentos que contemplem as distintas etapas do processo de inovação na empresa, bem como de instrumentos que consigam lidar com os diferentes tamanhos de empresas, e respectivamente, a capacidade de financiamento de cada uma. Ademais a questão setorial também é considerada no desenho de programas que procurem atender às diferentes necessidades e características dos setores. O que ainda se mantém como desafio é capacidade do governo de coordenar os instrumentos, principalmente quando executados por diferentes instituições e de avaliar o impacto da política na dinâmica inovativa das empresas.

Este trabalho busca contribuir um pouco neste sentido ao procurar articular o tipo de instrumento e o resultado da inovação, em termos de grau de novidade do produto lançado, ainda que o mesmo não possa ser atribuído somente ao suporte público.

\subsection{Incentivo fiscal}

O incentivo fiscal é umas das formas de apoio indireto à inovação, assim como os créditos tributários, depreciação acelerada e subsídios diretos. Os incentivos ao setor de informática são os mais antigos, tendo iniciado em 1984 com a instituição da reserva de mercado, através da Lei $\mathrm{n}^{0}$ 7.232, e perduraram até 1992. Por sua vez, os incentivos fiscais a este segmento iniciaram-se em $1991 \mathrm{com}^{2}$ Lei $^{\circ}$ 8.248, conhecida como Lei de Informática, que concedia incentivos fiscais ${ }^{4}$ às empresas nas áreas de informática e automação. As empresas deveriam investir 5\% do seu faturamento em $P \& D$ e, dentre o mesmo, pelo menos $2 \%$ deveriam obrigatoriamente ser aplicados em $P \& D$ via convênios com universidades ou institutos de pesquisa relacionados.

Em 2001, uma nova Lei de Informática foi sancionada (Lei ${ }^{0}$ 10.176). Além de manter o caráter da Lei anterior, ela introduziu algumas inovações na forma de conceder os incentivos. Dentre os mesmos destaca-se: (a) incentivos de IPI com redução progressiva; (b) manutenção integral do incentivo para a ZFM (Zona Franca de Manaus); (c) criação do Fundo Setorial de Informática (CTInfo); (d) vantagens para as regiões Nordeste, Norte e Centro-Oeste; (e) isenção para PMEs; (f) fim da cumulatividade dos mecanismos da Lei dentro da cadeia produtiva; (g) melhor governança e transparência (PACHECO, 2007). Em 2004, a Lei $\mathrm{n}^{\circ} 11.077$ introduziu modificações, estendendo os prazos dos benefícios até 2019, com uma redução gradativa das isenções fiscais ${ }^{5}$.

Salles-Filho et. al (2012) avaliaram as empresas que foram contempladas pela Lei de Informática entre 1998-2008. Dentre os resultados encontrados destaca-se que o faturamento das empesas quadruplicou no período e que o investimento em P\&D das empesas cresceu 30\% entre 2003-2007. Em comparação com os dados da PINTEC os autores encontraram que as empresas beneficiárias investiram 3 vezes mais do que as não beneficiárias.

\footnotetext{
${ }^{4}$ Os incentivos abrangiam: (a) dedução de até $1 \%$ do imposto de renda da compra de ações novas de empresas brasileiras de capital nacional que tenham a produção de bens e de serviços de informática como atividade principal; (b) dedução de até 50\% do imposto de renda das atividades de P\&D realizadas; (c) isenção do IPI dos produtos fabricados no país.

${ }^{5}$ No início da Lei, a base de cálculo referia-se ao faturamento bruto das empresas beneficiárias no mercado interno decorrente da comercialização de bens e serviços de informática, deduzidos os tributos correspondentes a tais comercializações. Em 2001, a base passou a ser o faturamento bruto dessas empresas no mercado interno, decorrente da comercialização de bens e serviços de informática, deduzidos os tributos correspondentes a tais comercializações, bem como o valor das aquisições de produtos incentivados. Já em 2004, a base passou a se referir ao faturamento bruto das beneficiárias no mercado interno, decorrente da comercialização de bens e serviços de informática, incentivados pela Lei (SALLES-FILHO et. al, 2012).
} 
Ademais da Lei de Informática cabe destacar os Programas de Desenvolvimento Tecnológico da Indústria ${ }^{6}$ e da Agricultura (PDTI e PDTA), A Lei do Bem e a Lei n ${ }^{0}$ 11.774/2008 (que faz uma revisão da Lei do Bem). Os incentivos fiscais à inovação foram introduzidos pela Lei $n^{\circ}$ 8.661/93, que instituiu os Programas de Desenvolvimento Tecnológico da Indústria (PDTI) e da Agricultura (PDTA). Dentre os incentivos introduzidos pelos programas estão: a possibilidade de deduzir parte dos gastos com P\&D do IRPJ (Imposto de Renda Pessoa Jurídica); depreciação acelerada incentivada em duas vezes dos investimentos em máquinas e equipamentos destinados à inovação; dedução de despesas com royalties e assistência técnica. Segundo Araújo (2012), 110 firmas acessaram o PDTI entre 1994 e 2004, através de 160 projetos de inovação, sendo que a maior parte das firmas que acessaram o PDTI era composta por empresas transnacionais ${ }^{7}$. Uma das razões para a baixa adesão ao Programa no período considerado era a burocracia e a falta de informação envolvida no acesso às deduções, além da necessidade de aprovação prévia.

A partir da implementação da Lei do Bem ${ }^{8}$ em 2005, os incentivos fiscais tornaram-se mais simples para as empresas, eliminando a necessidade de autorização prévia. Segundo Zucoloto (2012), além de simplificar o acesso, a Lei ampliou os mecanismos de apoio vigentes. A Lei do Bem prevê dedução de 160\% das despesas com inovação no cômputo da base de cálculo do imposto de renda, dedução de $50 \%$ do IPI na compra de máquinas e equipamentos para P\&D, depreciação acelerada destes equipamentos e amortização acelerada de bens intangíveis usados em P\&D. Em 2006130 empresas foram contempladas pelo benefício e em 2013 este número já era 977 representando um crescimento de cerca de 650\%. Segundo dados do Relatório Anual de Atividades de P\&D\&I do MCTI (Ministério de Ciência e Tecnologia), a renúncia fiscal cresceu 65\% em 2013 na comparação com 2012, saindo de $\mathrm{R}$ \$ 1,04 bilhão para R 1,58 bilhão ${ }^{9}$.

Segundo Zucoloto (2012), a Lei do Bem é um dos mecanismos mais utilizados pelas multinacionais, que representam cerca de 35\% das empresas beneficiadas. Mesmo considerando que muitas delas já promoviam atividades de $\mathrm{P} \& \mathrm{D}$ antes, vale considerar que as empresas podem optar por expandir seus gastos na área em virtude da redução de custos, ou até mesmo instalar no Brasil atividades de P\&D que poderiam estar em subsidiárias de outros países, o que pode ser favorável ao permitir o transbordamento dos benefícios da inovação para outras firmas. Zucoloto (2012) argumenta que a política de incentivo ao P\&D no Brasil não ocorre como contrapartida ao recebimento de outros investimentos, como em outros países. Assim, uma razão para que a tecnologia utilizada pelas multinacionais não gere tantos transbordamentos para o restante da economia seria também o fato do Brasil ter utilizado estímulos de atração ao investimento externo sem a exigência de contrapartidas. A estratégia pode ter sido exitosa para financiar e construir uma estrutura produtiva mais completa, mas não foi capaz de estimular a internalização das atividades de P\&D dessas empresas no Brasil, gerando capacidades internamente ao país.

Para Araújo (2012) os incentivos fiscais apresentam vantagens importantes para promoção da inovação dado seu baixo custo administrativo para o governo e sua maior flexibilidade, permitindo que a empresa decida sobre o desenvolvimento da inovação e o volume de gastos. Porem, há algumas críticas acerca deste tipo de incentivo. Corder (2006) afirma que os incentivos fiscais podem contribuir para aumentar o investimento empresarial em $\mathrm{P} \& \mathrm{D}^{10}$, mas acabam incentivando principalmente as empresas que já realizavam tais atividades, funcionando, portanto, mais como um prêmio do que como um incentivo. A

\footnotetext{
${ }^{6}$ O PDTI tinha a finalidade de estimular investimentos privados em pesquisa e inovação por meio da dedução do IR e do crédito fiscal incidindo no Imposto de Renda sobre Pessoa Jurídica (IRPJ), bem como no Imposto sobre Operações Financeiras (IOF). A legislação possibilitava, aos participantes desse programa, propor projetos constituídos ou por uma empresa, isoladamente, ou por empresas associadas a instituições de pesquisa.

${ }^{7}$ As análises feitas neste texto não consideram origem do capital da empresa uma vez que este detalhamento foi negado pela PINTEC para preservar a confidencialidade dos dados fornecidos.

${ }^{8}$ Além da Lei do Bem, outros avanços podem ser ilustrados pela Lei de Biossegurança, que viabilizou a pesquisa com organismos geneticamente modificados e com células-tronco e pela Lei da Informática, que teve os benefícios fiscais previstos estendidos para 2019.

${ }_{9}^{9}$ Disponível em: http://www.mct.gov.br/upd_blob/0238/238494.pdf

10 Para os empresários entrevistados por Corder (2006), o abatimento de impostos sobre insumos importados seria mais eficaz do que as modalidades oferecidas atualmente, uma vez que para gerar tecnologias, elas dependem muito de insumos importados, sem similares nacionais, cuja aquisição onera muito seus custos de produção.
} 
título ilustrativo, Zucoloto (2012) mostra que 95\% das empresas que acessaram os incentivos fiscais oferecidos a partir da Lei do Bem já promoviam atividades de P\&D.

Além disso, Araújo (2012) destaca principalmente duas limitações dessa forma de financiamento: estímulo à execução de projetos de inovação mais rentáveis, menos incertos e de prazo mais curto; beneficiamento às empresas maiores. Isto acontece porque o sistema fiscal beneficia as empresas que adotam o sistema de lucro real (que normalmente são empresas maiores) uma vez que neste sistema os gastos em inovação podem ser deduzidos como despesa reduzindo assim os lucros apurados e o imposto a pagar.

\section{H1 - Incentivos fiscais estão associados a empresas maiores e com projetos inovativos menos incertos}

\subsection{Subvenção}

A subvenção é um mecanismo de apoio que incentiva diretamente o desenvolvimento de produtos e processos inovadores em empresas, através da aplicação de recursos públicos não reembolsáveis visando compartilhar com as empresas os riscos das atividades de P\&D. Os recursos estão vinculados a uma contrapartida da empresa beneficiada, que é estabelecida de acordo com o porte da empresa. Todas as empresas brasileiras que tenham sede e administração no país podem solicitar a subvenção independentemente de quem seja seu sócio majoritário.

No Brasil, a possibilidade de subvenção direta para P\&D empresarial de forma não reembolsável foi introduzida pela primeira vez com a Lei da Inovação de 2004, que estabelecia formas de financiamento direto de $P \& D$ nas empresas, por meio de uma modalidade específica de subvenção ao setor privado, além de definir um percentual mínimo dos recursos do FNDCT $^{11}$ para a subvenção econômica de atividades de inovação.

De forma complementar ao estabelecido pela Lei de Inovação, em 2005, a Lei do Bem estabeleceu um conjunto de incentivos às atividades de $P \& D$, envolvendo a concessão de subvenção pelas agências de fomento para a remuneração de pesquisadores e empregados em atividades de inovação tecnológica (Zucoloto, 2012).

Assim, desde 2006, vem ocorrendo a seleção de projetos em temas prioritários das políticas industriais e tecnológicas em vigor, através de editais. Segundo informações da FINEP, entre 2006 e 2014 1075 projetos foram apoiados, somando aproximadamente R\$ 2,5 bilhões de reais aprovados. Porém isso se concentrou fortemente no período entre 2006 e 2009, onde foram aprovados 76\% desses projetos, correspondendo a $72 \%$ desse valor liberado. O valor do apoio médio dos projetos nesse período foi de R\$ 2,2 milhões, o qual foi considerado por Cavalcante (2013) como baixo, sugerindo uma estratégia de pulverização de recursos beneficiando muito projetos pequenos com baixo impacto na competitividade global do país. Porém, Zucoloto (2012) argumenta que, nos primeiros editais, as áreas tecnológicas apoiadas apresentavam características horizontais que podiam ser contempladas por empresas de diversos setores permitindo uma dispersão das empresas apoiadas entre vários setores da economia brasileira. Segundo a autora, nos editais mais recentes, o aumento do foco e concentração da modalidade em algumas áreas tecnológicas pode ser considerado um avanço. Complementar a isso, o valor médio do apoio ficou sempre superior a R \$ 2 milhões entre 2010 e 2014, chegando a atingir em 2010 uma média de R \$ 3,7 milhões e R\$ 4,3 milhões em 2014. ${ }^{12}$.

Além da FINEP, o BNDES também oferece alternativas de apoio através de subvenção como o Fundo Tecnológico (FUNTEC), cujas operações são não-reembolsáveis e limitadas a 90\% do total dos projetos. O orçamento total do FUNTEC em 2010 foi de R \$ 80 milhões, e é dada prioridade a projetos nas áreas de energia renovável, meio ambiente, eletrônica, novos materiais e química fina (ARAÚJO, 2012).

Araújo (2012) chama a atenção também para o Programa PAPPE Subvenção, através do qual a FINEP estaria descentralizando o suporte à inovação ao fazer parceria com as Fundações Estaduais de Amparo à Pesquisa, que participariam da distribuição dos recursos, do cofinanciamento das chamadas públicas e da seleção. Assim os governos estaduais foram estimulados a fortalecer seus sistemas de apoio

\footnotetext{
${ }^{11}$ FNDCT - Fundo Nacional de Desenvolvimento Científico e Tecnológico

12 Essas informações sobre os projetos apoiados pela FINEP foram obtidas a partir de um pedido através da Lei de Acesso a Informação. A data utilizada para cada projeto foi a de referência indicada pela FINEP
} 
à inovação, a eleger prioridades estratégicas e formalizar suas Leis Estaduais de Inovação. Torres (2016) analisando empresas que foram contempladas pelo PAPPE em diversos Estados encontrou que "o programa, além de cobrir a lacuna do acesso ao financiamento, propicia o estabelecimento de relações de longo prazo entre setor produtivo e universidades, fundamental para a geração de conhecimentos e inovações” (p. 23).

Como discutido, a subvenção econômica é uma forma de financiamento público que compartilha riscos das atividades de $P \& D$, oferecendo recursos não reembolsáveis. Nesse sentido, as empresas que buscam essa forma de financiamento teriam maiores incentivos para arriscar e buscar inovações com maior grau de novidade. Porém, isso contraria Cavalcante (2013), pois este sugere que a subvenção vinha apoiando projetos pequenos com baixo impacto. Nesse sentido, não é possível afirmar qual o resultado dessas forças antagônicas. Por hipótese, imagina-se que a segunda força seja maior, resultando, portanto, no apoio a projetos mais inovadores.

H2 - A subvenção não está associada com um porte específico, mas tende a apoiar inovações com maior grau de novidade.

\subsection{Crédito}

Segundo Araújo (2012), o financiamento direto à inovação, feito através de empréstimos em condições mais favoráveis, é uma forma de garantir os investimentos necessários em algumas prioridades nacionais eleitas, e de oferecer apoio às pequenas empresas (em contrapartida aos incentivos fiscais, que muitas vezes são mais acessíveis às empresas maiores). A concessão de crédito em condições especiais voltado para atividades de inovação no Brasil se dá principalmente via BNDES e FINEP. Durante a década de 2000, houve aumento da participação do BNDES na concessão de linhas de crédito para inovação, especialmente a partir de 2004 devido às diretrizes da PITCE. A atuação do BNDES se dá através de crédito geral e setorial, venture capital, e do Cartão BNDES, que funciona como um cartão de crédito comum, podendo ser utilizado para despesas relacionadas à inovação e também como garantia em programas da FINEP.

A FINEP é uma empresa pública vinculada ao MCTI tendo como missão "Promover o desenvolvimento econômico e social do Brasil por meio do fomento público à Ciência, Tecnologia e Inovação (C,T\&I) em empresas, universidades, institutos tecnológicos e outras instituições públicas ou privadas” (RIO DE JANEIRO, 2015). É a principal entidade pública de fomento e financiamento à inovação para empresas brasileiras. O apoio direto às empresas se dá através de linhas de financiamento com taxas de juros subsidiadas, para o repasse de recursos reembolsáveis.

Conforme destacado anteriormente, as empresas de menor porte tem dificuldades em acessar benefícios tributários. Segundo Morais (2007), o apoio às atividades de inovação nas microempresas pode gerar resultados interessantes, uma vez que elas apresentam maior flexibilidade produtiva, viabilizando o redirecionamento das atividades com mais facilidade que uma empresa grande no caso de obterem sucesso em sua implementação de novos produtos e processos. Porém, é necessário considerar que ao contrário das multinacionais, é difícil para essas empresas diluírem os riscos inerentes ao processo inovativo, uma vez que um insucesso pode ser fatal para sua sobrevivência.

Além disso, as empresas de menor porte não possuem condições de financiar atividades voltadas à inovação com recursos próprios e também enfrentam maiores dificuldades de acesso a crédito em virtude de fatores como falta de ativos fixos para apresentar como garantias, documentações fiscais incompletas e baixa transparência nos registros contábeis e financeiros. Para Morais (2007), tal dificuldade se agrava quando o objetivo do empréstimo é o investimento em atividades relacionadas à inovação, em função dos riscos já mencionados e do longo prazo demandado para a finalização do processo.

Ao avaliar a efetividade das ações voltadas à microempresa, Zucoloto (2012) aponta para a diversificação e ampliação dos escopos e aumento da oferta de recursos. Além disso, a autora ressalta que a convocação das empresas por meio de editais públicos permite disputas com maior abrangência, visibilidade e concorrência. Porém, argumenta que a participação das empresas ainda é baixa, havendo, portanto, a necessidade de se ampliar o alcance geográfico dos programas, descentralizando os recursos por meio das instituições locais. 
Diante da importância crucial do acesso ao financiamento para as empresas de pequeno porte, algumas ações foram realizadas pelo governo federal para melhorar tal acesso. Dentre eles destaca-se o Fundo Verde-Amarelo, que abrigou duas linhas de atuação: o Programa de Estímulo à Interação Universidade-Empresa (apoia o surgimento de incubadoras e parques tecnológicos e apoia arranjos produtivos locais) e o Programa de Inovação para a Competitividade (atua com participação no capital de microempresas de base tecnológica).

Os fundos setoriais, que tiveram pouca eficácia na década de 1990 devido à baixa execução orçamentária e ao arcabouço legal que impedia a subvenção nas empresas, constituíram um importante instrumento de apoio nos anos 2000. Zucoloto (2012), explica que para que os fundos funcionem, primeiro é definido qual será sua fonte de receita ${ }^{13}$. Depois, é nomeado um comitê gestor capaz de contemplar os interesses do governo, do meio empresarial e da comunidade científica e tecnológica, para então definir o aparato legal e institucional que irá reger o fundo, bem como suas diretrizes básicas, área de atuação e seu regulamento operacional.

A aplicação dos recursos é feita por meio da contratação de projetos selecionados a partir de três tipos de instrumentos convocatórios: chamadas públicas, que selecionam as propostas que melhor respondam às características especificadas na convocatória; carta-convite, que é utilizada quando o ente público deseja restringir o número de concorrentes àquelas instituições de reconhecida capacidade técnica para atender ao objeto demandado; e encomenda, que é utilizada quando a especificidade enseja a convocação de uma determinada instituição ou pessoa de reconhecida experiência e capacidade técnica para o fim demandado (NASCIMENTO; OLIVEIRA, 2011).

Segundo Queiroz e Cavalcante (2012) execução orçamentária dos fundos setoriais entre 2001 e 2010, aumentou de R \$375,1 milhões para R \$2.788,6 milhões. Porém, Cavalcante (2013) nota que o valor médio dos projetos financiados pelos fundos setoriais na década de 2000 é de $\mathrm{R} \$ 335$ mil. Para o autor, este valor é baixo uma vez que não poderia cobrir projetos para áreas que demandam investimento mais alto como nanotecnologia. Assim, os recursos tendem a se destinar mais a inovações incrementais do que às radicais.

O presente estudo separa esse crédito entre aquele para compras de máquinas e equipamentos para inovar e para projetos de P\&D e Inovação, seguindo o questionário da Pesquisa de Inovação 2011 (IBGE, 2013). Entende-se que são atividades inovativas consideravelmente distintas e atreladas com inovações com graus de novidade distintos e portes distintos. Por exemplo, empresas maiores tendem a realizar mais gastos em $\mathrm{P} \& \mathrm{D}$ do que as empresas menores, além de possuírem recursos para incorrer em maiores riscos. Para exemplificar, segundo a PINTEC 2011 as pequenas empresas gastaram, em 2011, 0,43\% das suas receitas em atividades internas de $P \& D$ enquanto as grandes empresas gastaram 0,93\%. Além disso, 42\% dos gastos em atividades inovativas nas grandes empresas são para realizar P\&D internamente, enquanto nas pequenas esse valor é $12 \%$ (IBGE, 2013) ${ }^{14}$. Quando analisado os gastos na aquisição de máquinas e equipamentos, a parcela da receita gasta é de $2,1 \%$ para as pequenas empresas e $0,7 \%$ para as grandes empresas, correspondendo, respectivamente, a 57\% e 31\% do total gasto em atividade inovativa destas. Ou seja, o crédito a P\&D\&I tende a ir mais para grandes empresas enquanto o crédito para compra de máquinas e equipamentos para pequenas empresas.

H3 - Crédito para máquinas e equipamentos está atrelado a empresas de menor porte e inovações com menor grau de novidade (H3.1) enquanto o crédito para P\&D\&I, está relacionado com empresas maiores e inovações mais incertas e com maior grau de novidade (H3.2).

\section{Quadro 1 - Hipóteses a serem testadas sobre a relação entre tipo de apoio, porte e grau de novidade Incentivo Fiscal Subvenção Crédito para M\&E Crédito para P\&D\&I}

\footnotetext{
${ }^{13}$ As fontes mais comuns de receita nesse caso são contribuições incidentes sobre o resultado da exploração de recursos naturais pertencentes à União, parcelas do Imposto sobre Produtos Industrializados, e do CIDE (contribuição de intervenção no domínio econômico).

${ }^{14}$ Essa porcentagem varia consideravelmente entre setores, porém o presente estudo não realiza essa separação setorial. O motivo para isto será explicado no decorrer do estudo.
} 


\begin{tabular}{lcccccccc} 
& Porte & GN & Porte & GN & Porte & GN & Porte & GN \\
\hline H1 & Grande & Baixo & & & & & & \\
H2 & & & Indefinido & Alto & & & & \\
H3 & & & & & Pequena & Baixo & Grande & Alto \\
\hline
\end{tabular}

Fonte: Elaboração própria.

Legenda.: GN = Grau de novidade; H=Hipótese;

\section{A relação entre o tipo de financiamento e o grau de novidade da inovação de produto se diferencia de acordo com o porte das empresas?}

Na seção anterior mostrou-se, teoricamente, que há uma relação entre o porte das empresas e os tipos de financiamento obtidos por estas. Além disso, foram identificados indícios de que os diferentes tipos de financiamentos tenderiam a incentivar a implementação de inovações com diferentes graus de novidade ou, em outras palavras, em lidar com diferentes graus de incerteza.

Este seção busca analisar tais hipóteses a partir de dados obtidos através de uma tabulação especial da PINTEC para o período 2009-2011 (IBGE, 2013). Devido às restrições para divulgação dos dados, não foram possíveis análises setoriais dos mesmos. Nesse sentido, as análises compreendem tanto a indústria de transformação, os serviços e os setores de eletricidade e gás. O detalhamento setorial deve ser fruto de novos estudos, acessando, por exemplo, os microdados dessa pesquisa.

São analisados três tipos de financiamento ou apoio e três tamanhos ou portes de empresa. Os portes são: pequena (até 99 empregados); média (entre 100 e 499); grande (a partir de 500). Seguindo a discussão teórica, são analisados os seguintes tipos de apoio: (1) Subvenção econômica à P\&D e inserção de pesquisadores; (2) Incentivos Fiscais à P\&D e inovação tecnológica ou via Lei de Informática; (3) crédito, dividindo entre (3.1) crédito exclusivo para compras de máquinas e equipamentos utilizados para inovar (Compra de M\&E) e (3.2) crédito a projetos de P\&D e inovação (P\&D e inovação) ${ }^{15}$.

A seção está dividida em três subseções. A primeira analisa a relação entre o grau de novidade da inovação de produto e o tipo de apoio desconsiderando o porte, enquanto a segunda realiza essa análise novamente, mas por porte das empresas. Já a terceira busca sintetizar os resultados encontrados, visando responder as hipóteses anteriores. As tabelas utilizadas para cada estão em anexo.

\footnotetext{
15 A PINTEC 2011 utiliza o termo “financiamento” ao invés de crédito. Porém, para ser coerente com a discussão teórica, será utilizado "crédito" ao invés de "financiamento", afinal, para o presente estudo, o crédito é uma das formas de se financiar ou apoiar a inovação nas empresas.
} 


\subsection{Grau de novidade da inovação de produto e tipo de apoio governamental recebido, independente do porte das empresas.}

\section{Gráfico 1 - Porcentagem de empresas inovadoras em produto com o determinado grau de novidade, por tipo de apoio recebido.}

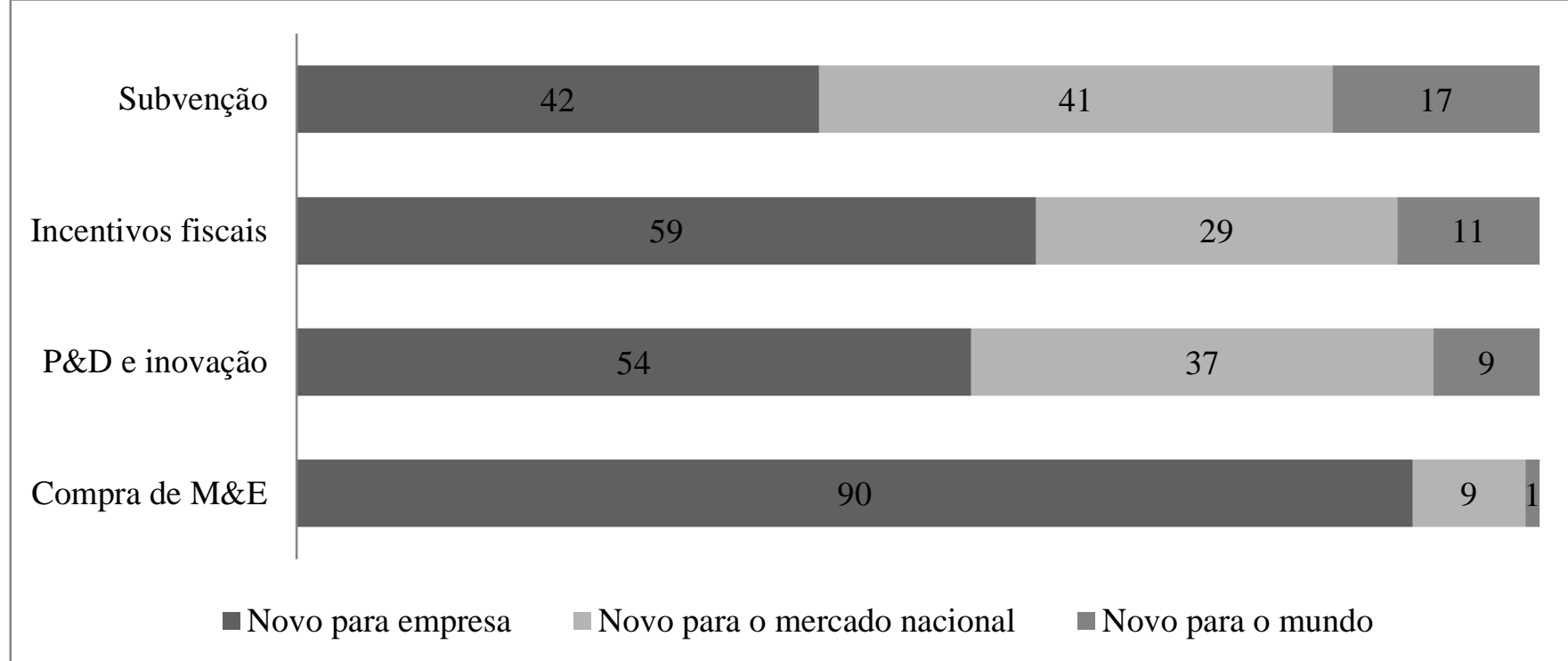

Fonte: PINTEC 2011 (IBGE, 2013). Elaboração Própria

Primeiro ponto interessante a ser observado é para o crédito destinado às compras de máquinas e equipamentos para inovar. Observa-se que esse tipo de apoio está atrelado principalmente com uma inovação nova apenas para empresa, apresentando a maior porcentagem dentre todos os tipos de apoio. Já para inovações com maior grau de novidade, esse tipo de apoio apresentou a menor porcentagem tanto para produtos novos para o mercado nacional quanto para o mercado externo.

Um perfil diretamente oposto a este é o apresentado pelas empresas que conseguiram subvenções econômicas. Dentre estas, a porcentagem de empresas que receberam esse tipo de apoio e inovaram em produtos novos para a própria empresa ou para o mercado nacional são similares. Isso ocorre apenas nesse tipo de apoio. Nos demais tipos a porcentagem de empresas que inovaram em produto novo para a própria empresa é, pelo menos, 17 pontos percentuais (pp) superiores à porcentagem de empresas que inovaram em produtos novos para o mercado nacional. Além disso, empresas inovadoras que receberam subvenções econômicas apresentaram as maiores taxas de inovação para o mercado mundial (6pp superior à segunda maior taxa, apresentada pelas empresas com incentivos fiscais).

Um ponto interessante é a comparação entre o comportamento das empresas que receberam incentivos fiscais e aquelas que tiveram crédito para projetos de $\mathrm{P} \& \mathrm{D}$ e inovação (P\&D\&I). Estas apresentam porcentagens relativamente similares para os três tipos de inovações de produtos, especialmente para as novas para o mundo (2pp a mais para as empresas com incentivos fiscais). Porém, é observada uma porcentagem maior de empresas que inovaram para si e que receberam incentivos fiscais, mas a porcentagem de empresas que inovaram em produtos para o mercado nacional é menor para aquelas que tiveram esse tipo de apoio, em comparação com as empresas que receberam financiamento para P\&D e inovação. É interessante observar que a literatura aponta que, tanto os incentivos fiscais quanto o financiamento a $\mathrm{P} \& \mathrm{D}$, tendem a ser captados por empresas de grande porte, pois, respectivamente, essas empresas podem ter o sistema de contabilidade do lucro exigido para buscar os incentivos fiscais e elas tendem a realizar mais $P \& D$ e ter recursos humanos que possam redigir os projetos de P\&D\&I, o que elevaria as chances de buscar financiamento para tal (ARAÚJO, 2012). Essa suposição será analisada a seguir.

Os resultados encontrados corroboram parcialmente, as suposições feitas pela literatura consultada. O crédito para máquinas e equipamentos claramente está vinculado a inovações menos incertas ou para a própria empresa, enquanto os créditos para $\mathrm{P} \& \mathrm{D}$ e Inovação não geram tantas inovações com maior grau de novidade quanto era de se esperar de tais atividades inovativas. Nesse sentido, apesar das atividades de 
P\&D serem essenciais para tais inovações, essa modalidade de financiamento tende a gerar mais inovações apenas para a empresa ou para o Brasil, devido à preocupação que as empresas tem em gerar receitas para pagar as dívidas contraídas, o que impede que se arrisquem em projetos mais arrojados. Além disso, a literatura aponta que as empresas brasileiras tendem a focar mais no Desenvolvimento do que na pesquisa de fato, limitando a capacidade inovativa destas.

Já para os incentivos fiscais, os indicativos são dúbios: é o segundo maior em termos de participação de inovadoras em produtos apenas para a empresa, mas também é o segundo em termos de participação de inovadoras para o mundo. Assim, não se pode afirmar que, necessariamente ele esteja atrelado a níveis mais incertos ou de novidade da inovação. Já a subvenção está relacionada com a maior participação tanto de empresas inovadoras para o país quanto para o mundo. Como salientado, essa forma de apoio dá mais liberdade para as empresas arriscarem ao compartilhar riscos. A seguir é analisado esse comportamento de acordo com o porte.

\subsection{Grau de novidade da inovação de produto e tipo de financiamento recebido, por porte das empresas}

Análises similares às anteriores são realizadas a seguir considerando o porte das empresas, buscando testar argumentos apresentados pela literatura de que determinados tipos de financiamento seriam mais acessíveis a empresas grandes. O gráfico abaixo mostra o tipo de apoio predominante para cada porte de empresas e também o principal porte atendido por cada tipo de apoio em termos de número de empresas.

\section{Gráfico 2 - Tipo de apoio predominante para cada porte ${ }^{16}$.}

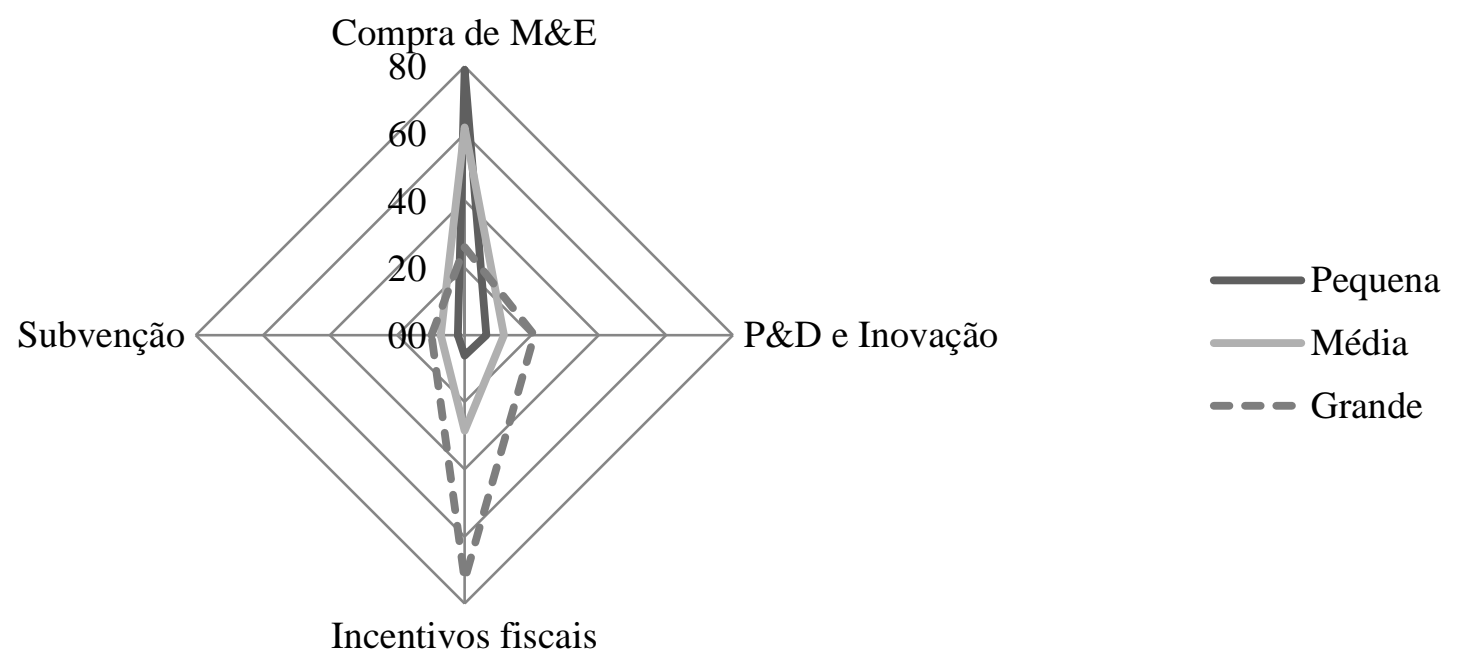

Fonte: PINTEC 2011 (IBGE, 2013). Elaboração Própria

O gráfico acima mostra um comportamento diametricamente oposto entre as empresas pequenas e as grandes quanto ao tipo de apoio recebido. Enquanto $79 \%$ das pequenas empresas inovadoras (seja em produto ou processo) que tiveram apoio do governo entre 2009-2011 o fizeram via crédito para compra de máquinas e equipamentos, apenas $26 \%$ das grandes empresas apoiadas teve esse tipo de financiamento. Já quanto aos incentivos fiscais, observa-se que as grandes empresas inovadoras que buscam apoio o adquirem principalmente via incentivos fiscais (73\% para as grandes empresas e 6,2\% para as pequenas empresas). Essa diferença entre grande e pequena empresa também é captada pela modalidade "Crédito para projetos de P\&D\&I", onde $21 \%$ das grandes empresas inovadoras com apoio receberam esse tipo de apoio, enquanto 6,6\% das pequenas inovadoras com apoio tiveram-no. Assim, há indícios de que, parcialmente, a hipótese 1 (incentivos fiscais são destinados a empresas maiores) e 3 (quanto ao crédito para P\&D\&I e Compra de máquinas e equipamentos) não sejam rejeitadas.

\footnotetext{
${ }^{16}$ Essa razão foi calculada assim: (Número de empresas inovadoras do porte X que receberam o apoio A)/(Número de empresas do porte $\mathrm{X}$ que receberam qualquer tipo de apoio)
} 
Já sobre a subvenção (hipótese 2), esta talvez seja rejeitada pois há indícios de que atenda principalmente grande e média empresa. As médias empresas estiveram sempre em um meio termo, pois, também buscam principalmente crédito para compra de máquinas e equipamentos (similar às pequenas empresas), mas os incentivos fiscais é a segunda forma de apoio mais usada. Além disso, utilizam de subvenção tanto quanto as grandes empresas.

Uma análise distinta é realizada a partir do gráfico 3. Nesta, busca-se avaliar a participação de cada porte em determinado tipo de apoio. Isso é feito através da razão entre o número de empresas de determinado porte que receberam o tipo de apoio em questão e o número de empresas inovadoras que receberam determinado apoio.

\section{Gráfico 3 - Principal porte de empresas atendido por cada tipo de apoio: porcentagem de empresas} inovadoras que receberam determinado apoio por porte.

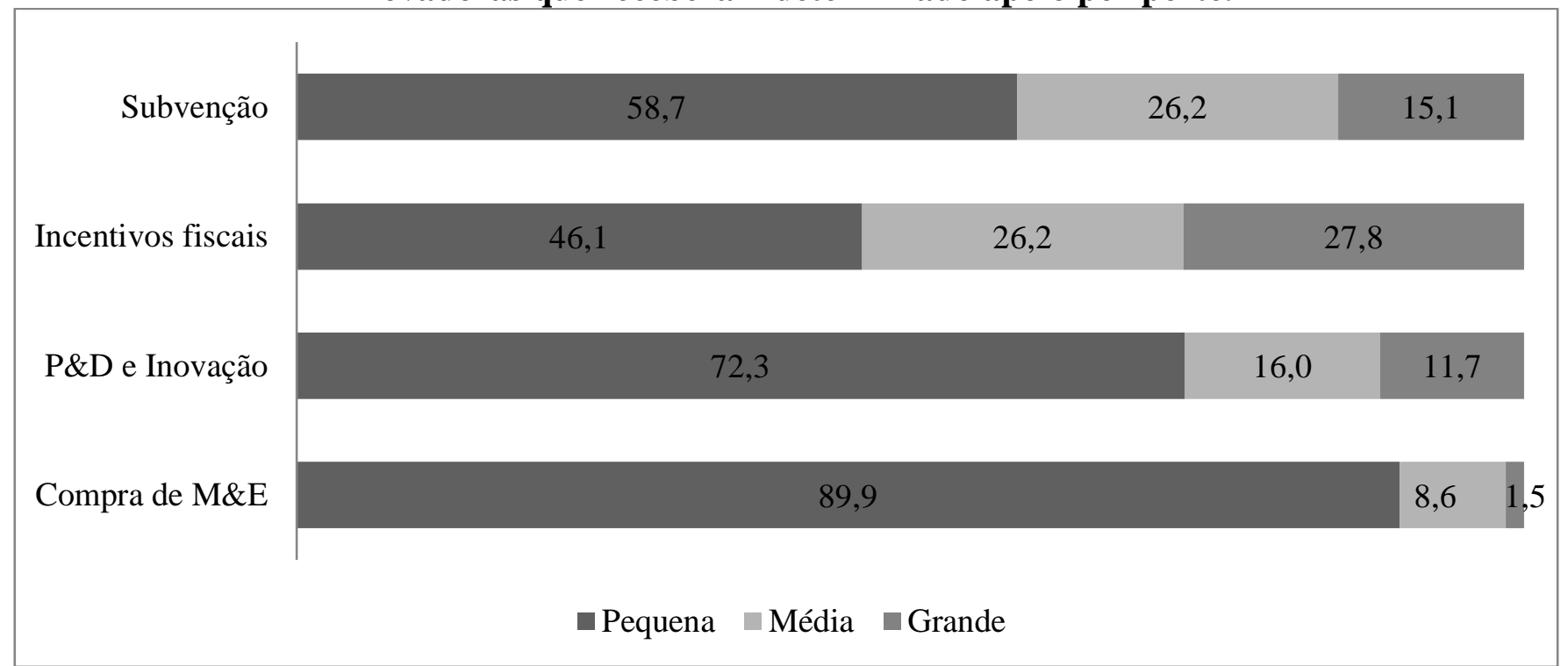

Fonte: PINTEC 2011 (IBGE, 2013). Elaboração Própria

Através deste gráfico, nota-se que, para todos os tipos de apoio, as empresas de pequeno porte correspondem à maior parcela de empresas inovadoras que receberam o apoio em questão. A maior participação dessas empresas é no financiamento para compra de máquinas e equipamentos (89,9\%) e a menor participação é observada nos incentivos fiscais. Novamente, de forma oposta, as grandes empresas participam mais dos incentivos fiscais $(27,8 \%)$ e menos do financiamento para máquinas e equipamentos. Já as empresas de médio porte possuem maior participação nos incentivos fiscais e subvenção e menor participação também no financiamento para máquinas e equipamentos.

Porém, esses resultados não podem ser interpretados como uma concentração de determinado tipo de apoio em um porte específico, pois não foi ponderado o fato de que existem mais empresas inovadoras de pequeno porte do que empresas inovadoras de grande porte, por exemplo. A ausência dessa ponderação pode resultar a interpretações equivocadas a respeito da concentração de determinado tipo de apoio em um porte específico.

Visando minimizar isso foi calculado um indicador de concentração do tipo de apoio no porte das empresas, denominado ICAP. Neste é calculada a razão entre a participação do porte em um tipo de apoio específico em relação à participação desse porte no total de empresas que receberam qualquer tipo de apoio. Em termos matemáticos, essa razão é exposta assim:

Onde:

$$
\operatorname{ICAP}(\alpha, \rho)=\frac{P_{\rho} A_{\alpha}}{P_{T} A_{\alpha}} / \frac{P_{\rho} A_{T}}{P_{T} A_{T}}
$$

- $\quad \operatorname{ICAP}_{(\alpha, \mathrm{P})}=$ Indicador de Concentração do tipo de Apoio $\alpha$ no Porte $\rho$.

- $\quad \mathrm{P}_{\rho} \mathrm{A}_{\alpha}=$ número de empresas inovadoras do porte $\rho$ que receberam o tipo de apoio $\alpha$ 
- $\quad \mathrm{P}_{\mathrm{T}} \mathrm{A}_{\alpha}=$ total de empresas, independente do porte, que receberam o tipo de apoio $\alpha$

- $\quad \mathrm{P}_{\rho} \mathrm{A}_{\mathrm{T}}=$ número de empresas inovadores do porte $\rho$ que receberam algum tipo de apoio

- $\quad \mathrm{P}_{\mathrm{T}} \mathrm{A}_{\mathrm{T}}=$ número de empresas inovadoras, independente do porte, que receberam algum tipo de apoio.

Dessa forma, quando esse indicador é maior do que 1 para o apoio $\alpha_{1}$ e $\rho_{1}$, tem-se que a participação de empresas inovadoras do porte $\rho_{1}$ é superior para o apoio $\alpha_{1}$ em comparação com sua participação dentre as empresas inovadoras com apoio, independente do tipo deste. Nesse caso, interpreta-se como um indício de concentração desse tipo de apoio $\alpha$ nas empresas do porte $\rho$.

Tabela 1 - Indicador de concentração do tipo de apoio governamental em determinado porte.

\begin{tabular}{lcccc}
\hline & Compra de M\&E & P\&D e Inovação & Incentivos fiscais & Subvenção \\
\hline Pequena & 1,0545 & 0,8488 & 0,5407 & 0,6886 \\
Média & 0,8253 & 1,5281 & 2,5046 & 2,5058 \\
Grande & 0,3493 & 2,7018 & 6,4095 & 3.4949 \\
\hline
\end{tabular}

Fonte: PINTEC 2011 (IBGE, 2013). Elaboração Própria

Observa-se que o financiamento para a compra de máquinas e equipamentos para inovar é concentrada especialmente nas pequenas empresas e pouco concentrada nas grandes empresas, porém essa concentração não é tão elevada quanto destacava o gráfico anterior. Além disso, observa-se que as pequenas apresentam indicador superior a um apenas para esse tipo de financiamento. O menor valor apresentado pelas empresas desse porte está nos incentivos fiscais $(0,5407)$, modalidade de apoio em que as grandes empresas apresentam o maior valor. A participação das grandes empresas inovadoras nessa modalidade é equivalente a 6,4 vezes a sua participação geral no apoio à inovação. Esse comportamento diametricamente oposto entre pequenas e grandes empresas já havia sido mostrado no gráfico 2. Ainda para as grandes empresas, o segundo maior valor é para subvenção, seguida pelo financiamento para P\&D\&I. Inclusive, esse porte é que apresenta os maiores valores para todos os demais tipos de apoio, indicando que as grandes empresas tendem a concentrar diversos tipos de apoio, especialmente os incentivos fiscais, exceto o financiamento para compra de máquinas.

Sobre as médias empresas, observa-se que nesta análise apresentam comportamentos mais próximos das grandes empresas do que das pequenas empresas quanto aos tipos de apoio. Os menores indicadores também são para o crédito para máquinas e equipamentos (o único menor do que um), enquanto que os maiores valores são para incentivos fiscais e subvenção (são praticamente equivalentes a 2,5).

Porém, para avaliar totalmente as hipóteses anteriores, é necessário relacionar o porte das empresas, tipo de financiamento (ou apoio) e o grau de novidade da inovação de produto. Isso é realizado a partir dos gráficos 4, 5 e 6 . Além de avaliar as hipóteses anteriores, esses gráficos permitem responder duas perguntas adicionais, que direcionam tais análises: (1) qual tipo de apoio está atrelado com uma parcela maior de empresas inovadoras para o mundo para cada porte? (2) qual tipo de apoio está atrelado com uma parcela menor de inovadoras apenas para empresa para cada porte? A análise se inicia pelas pequenas empresas. 
Gráfico 4 - Porcentagem de pequenas empresas inovadoras em produtos com determinado grau de novidade, por tipo de apoio recebido.

\begin{tabular}{|c|c|c|c|}
\hline \multicolumn{4}{|c|}{ Inovação em Produto - Pequena empresa } \\
\hline Subvenção & 43 & & 13 \\
\hline Incentivos fiscais & 78 & 18 & 4 \\
\hline P\&D e inovação & 58 & & 4 \\
\hline Compra de M\&E & 92 & & 81 \\
\hline
\end{tabular}

Fonte: PINTEC 2011 (IBGE, 2013). Elaboração Própria

O primeiro ponto a ser observado é que o tipo de apoio que está atrelado à menor parcela de inovações apenas para a pequena empresa é a subvenção (44\%), seguida pelo crédito para realização de P\&D\&I (58\%), incentivo fiscal (78\%) e crédito para compra de máquinas e equipamentos (92\%).

Quanto à parcela de pequenas empresas que inovaram para o mundo, a importância da subvenção aparece novamente, sendo a que apresenta a maior parcela de empresas que inovaram para o mundo (13\%), seguida pelo crédito a P\&D\&I (4,3\%), incentivos fiscais (3,95\%) e crédito para compras de máquinas e equipamentos (0,57\%). Nesse sentido, é interessante notar que a subvenção já havia sido atrelada a inovações para o mundo ao analisar sem considerar o porte das empresas (vide gráfico 1), porém, é um tipo de apoio obtido apenas por 1,9\% das pequenas empresas inovadoras. Nesse sentido, o acesso a esse tipo de apoio pode ser um fator importante para que pequenas empresas concorram globalmente. É importante frisar que não foi realizada uma separação setorial, de modo que esse resultado possa ter sofrido influência de empresas dos setores de serviços intensivos em conhecimento, por exemplo, onde as empresas de menor porte tendem a ser mais inovadoras.

\section{Gráfico 5 - Porcentagem de médias empresas inovadoras em produtos com determinado grau de novidade, por tipo de apoio recebido.}

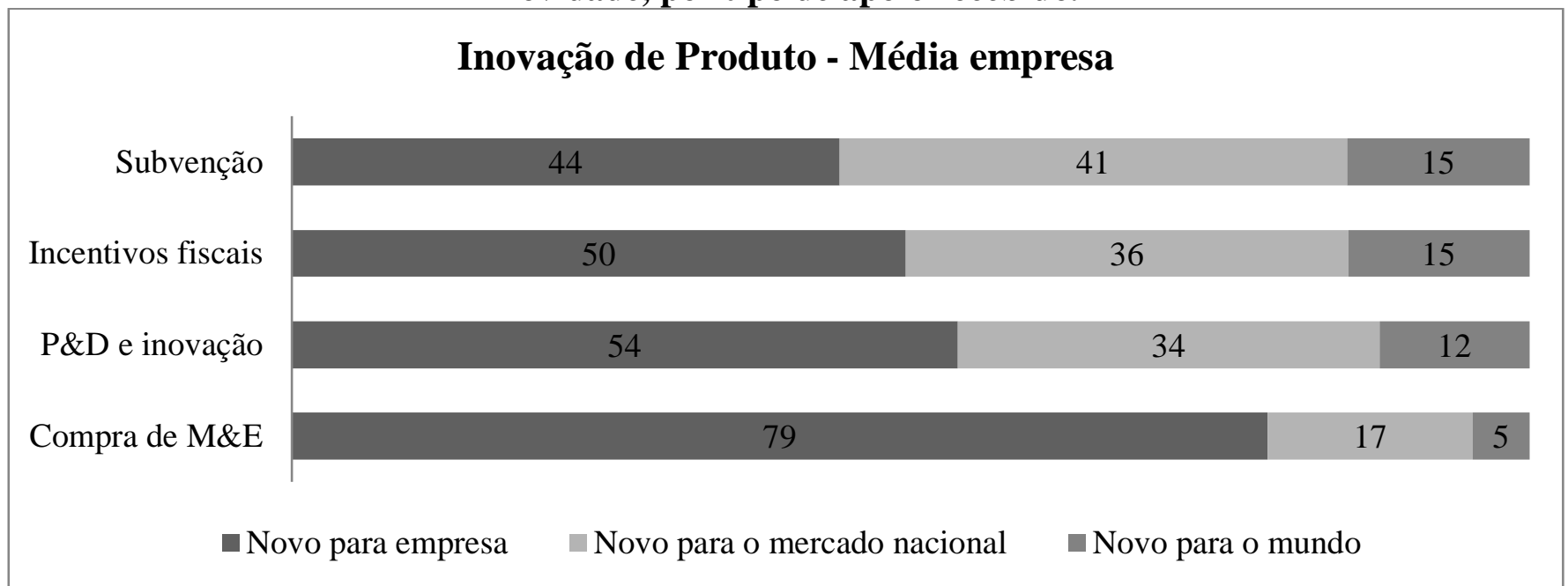

Fonte: PINTEC 2011 (IBGE, 2013). Elaboração Própria

O caso das empresas médias apresenta algumas similaridades com o caso das pequenas empresas. A primeira delas remete ao crédito para compra de máquinas e equipamentos como sendo o tipo de apoio mais próximo da inovação em produtos com menor grau de novidade. Outro ponto de congruência é a 
subvenção econômica. Esta modalidade de apoio continua sendo aquela com menor parcela de empresas inovadoras em produtos novos apenas para a empresa, porém, em oposição às pequenas empresas, a diferença entre a subvenção e os incentivos fiscais é consideravelmente inferior (4pp no caso das médias empresas e 34,5pp para as pequenas empresas). Além disso, a diferença entre a subvenção e os créditos para P\&D e inovação (P\&D\&I) também são relativamente menores no caso das médias empresas: 10pp para estas e 14,6pp para pequenas empresas.

Complementar a isso, observa-se que a subvenção para as médias empresas não está relacionada com uma parcela de empresas inovadoras para o mundo substancialmente superior à parcela apresentada por outros tipos de apoio, como os Incentivos Fiscais e o Crédito para P\&D\&I. Subvenção e incentivos fiscais apresentam 14,7\% e 14,6\% de médias empresas inovadoras em produtos para o mundo respectivamente, enquanto o crédito para $P \& D \& I$ tem $12 \%$ de empresas implementadoras desse tipo de inovação.

Este resultado pode sugerir uma capacidade maior de empresas médias em arcar com investimentos mais incertos quando comparadas com as empresas pequenas, uma vez que o crédito para P\&D também estaria relacionado a inovações com maior grau de novidade neste caso. O mesmo vale para os incentivos fiscais. Já as empresas pequenas se mostram mais dependentes da subvenção para a geração de inovações mais incertas (novas para o mundo).

É possível observar também que para as médias empresas a diferença entre incentivos fiscais e crédito para $\mathrm{P} \& D \& I$ é pequena quanto à parcela de empresas inovadoras em produtos novos para o mercado nacional, quando comparado com as pequenas empresas. Para as médias empresas, essa diferença é de 1,6pp a favor dos incentivos fiscais, enquanto que para as pequenas empresas essa diferença é de 19,5pp a favor do crédito à P\&D\&I. Portanto, há mais indícios de que os incentivos fiscais estão mais relacionados com inovações com maior grau de novidade para as médias empresas vis a vis o crédito à P\&D\&I, quando comparado com as pequenas empresas. De certa forma, isso contraria parcialmente as hipóteses 1 e 3, na qual os incentivos fiscais estariam relacionados com inovações mais locais e menos incertas, enquanto o $\mathrm{P} \& \mathrm{D}$, às inovações para o mundo. Porém, ambos os tipos de apoio seriam destinados a empresas maiores, as quais são analisadas a seguir.

\section{Gráfico 6 - Porcentagem de grandes empresas inovadoras em produtos com determinado grau de novidade, por tipo de apoio recebido}

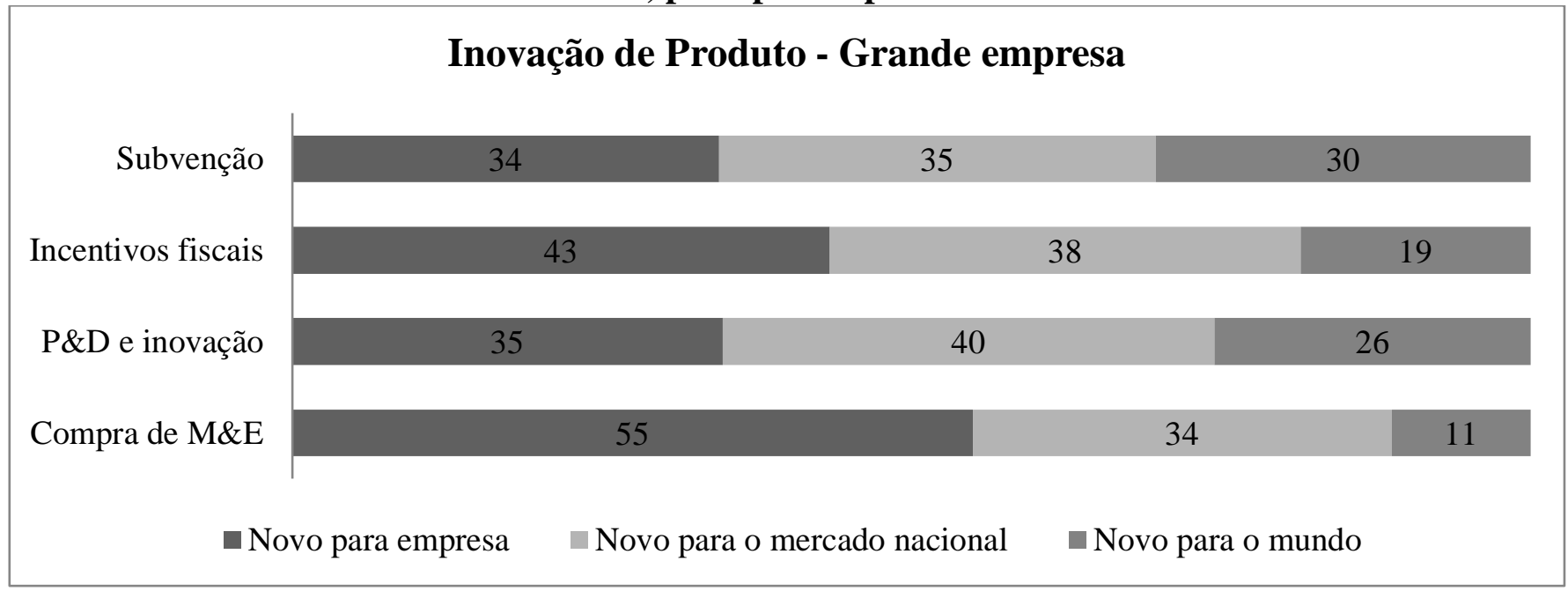

Fonte: PINTEC 2011 (IBGE, 2013). Elaboração Própria

Primeiramente, observa-se que a parcela de empresas inovadoras para o mercado nacional é relativamente similar em todos os tipos de apoio, inclusive no crédito para máquinas e equipamentos. Para exemplificar, a diferença entre o tipo de apoio com a maior parcela de empresas inovadoras para o mercado nacional e o tipo de apoio com a menor parcela destas era de 35,6pp para pequenas, 24,4pp para médias e 5,9pp para as grandes. Nesse sentido, não são identificadas grandes diferenças entre os tipos de apoio e a inovação para o mercado nacional no caso da grande empresa, o que poderia indicar que, para grandes 
empresas, um tipo de apoio específico não influencia no grau de novidade da inovação de produto, sendo mais relevante sua estratégia interna.

Porém, alguns pontos devem ser ressaltados. O crédito para compras de máquinas e equipamentos se mantém como aquele com a maior parcela de empresas inovadoras apenas para a empresa, porém, essa porcentagem é consideravelmente inferior às apresentadas pelos demais tipos de apoio (40\% inferior à pequena empresa e $30 \%$ à média empresa). Ademais, o subsídio continua vinculado à maior parcela de empresas inovadoras para o mundo, seguido pelo financiamento à P\&D\&I e os incentivos fiscais, de modo similar às pequenas empresas, mas com uma porcentagem consideravelmente superior (2,3 vezes a parcela para o financiamento a P\&D\&I e 6,5 vezes para incentivos fiscais). Também vale destacar que, pelo gráfico 2, $73 \%$ das grandes empresas inovadoras com apoio receberam incentivos fiscais (esta sendo a maior porcentagem), porém esse apoio é apenas o terceiro em termos de empresas inovadoras em produtos novos para o mundo. Se comparado com as empresas médias com apoio, o incentivo fiscal foi obtido por 28,5\% destas, mas é o apoio com maior parcela de empresas inovadoras para o mundo, junto com o subsídio. Ou seja, os incentivos fiscais para as grandes empresas podem ser menos importantes para inovações com maior grau de novidade do que para as médias empresas. Isso pode ser devido à forte presença de empresas multinacionais dentre as grandes empresas no Brasil, pois estas tendem a não gerar inovações mais incertas (ou novas) no país e sim na sua matriz. Para as grandes empresas, os principais incentivos para essa inovação mais incerta são as subvenções, seguido pelos créditos à P\&D\&I. Dessa forma, a hipótese 1 (incentivos) não pode ser refutada, afinal as empresas maiores concentram os incentivos fiscais, mas este não é o principal em termos de inovações mais incertas ou para o mundo e sim as subvenções (hipótese 2) e o crédito para P\&D (hipótese 3).

\subsection{Síntese da relação entre porte, grau de novidade da inovação em produto e tipo de apoio governamental}

O quadro 2 a seguir visa sintetizar os argumentos apresentados anteriormente.

\section{Quadro 2 - Síntese da relação entre porte, grau de novidade da inovação em produto e tipo de apoio governamental}

\begin{tabular}{|c|c|c|c|c|c|}
\hline \multirow[t]{2}{*}{ Porte } & \multirow{2}{*}{$\begin{array}{l}\text { Principal } \\
\text { apoio } \\
\text { recebido }\end{array}$} & \multirow{2}{*}{$\begin{array}{l}\text { Concentra mais } \\
\text { qual apoio? }\end{array}$} & \multicolumn{3}{|c|}{$\begin{array}{l}\text { Tipo de apoio com maior parcela de empresas inovadoras em } \\
\text { produtos novos para: }\end{array}$} \\
\hline & & & Empresa & Mercado Nacional & Mundo \\
\hline $\mathrm{P}$ & $\begin{array}{l}\text { Compra de } \\
\text { M\&E }\end{array}$ & Compra de M\&E & $\begin{array}{l}\text { Compra de } \\
\text { M\&E }\end{array}$ & Subvenção & Subvenção \\
\hline M & $\begin{array}{l}\text { Compra de } \\
\text { M\&E }\end{array}$ & $\begin{array}{l}\text { Incentivo Fiscal e } \\
\text { Subvenção }\end{array}$ & $\begin{array}{l}\text { Compra de } \\
\text { M\&E }\end{array}$ & Subvenção & $\begin{array}{l}\text { Subvenção e } \\
\text { Incentivo Fiscal }\end{array}$ \\
\hline G & $\begin{array}{l}\text { Incentivos } \\
\text { Fiscais }\end{array}$ & Incentivos Fiscais & $\begin{array}{l}\text { Compra de } \\
\text { M\&E }\end{array}$ & $\begin{array}{l}\text { P\&D e Inovação e } \\
\text { Incentivos Fiscais }\end{array}$ & Subvenção \\
\hline Geral & & & $\begin{array}{l}\text { Compra de } \\
\text { M\&E }\end{array}$ & $\begin{array}{l}\text { Subvenção e P\&D e } \\
\text { Inovação }\end{array}$ & Subvenção \\
\hline
\end{tabular}

Fonte: Elaboração Própria.

Legenda para Porte: $\mathrm{P}$ = Pequena; M=Média; Grande empresa; Geral=Sem considerar o porte.

Pelo quadro 2 tem-se que a relação entre tipo de apoio e o grau de novidade da inovação se difere entre os portes especialmente para as inovações em produto para o mercado nacional. Ainda que as magnitudes sejam diferentes, em todos os portes o crédito para compra de máquinas e equipamentos para inovar foi a modalidade de apoio com maior parcela de empresas inovadoras em produtos para a empresa, enquanto a subvenção foi o principal apoio atrelado a inovações para o mundo em todos os portes, apesar de dividir a primeira posição com incentivos fiscais para as empresas médias. A importância da subvenção para as inovações para o país se mantém para as pequenas e médias empresas, mas perde relevância para as grandes empresas. Nesse caso, o financiamento para P\&D e Inovação e os incentivos fiscais são os principais atrelados com essa inovação para o mercado nacional. 
É importante contrastar esse resultado com o principal apoio obtido pelas empresas inovadoras (coluna 1 e 2 no quadro 2 acima). Enquanto a maior parte das empresas médias inovadoras receberam apoio principalmente via financiamento para compra de máquinas e equipamentos, estas concentraram principalmente os apoios do tipo "Incentivo fiscal" e "Subvenção Econômica”, quando controlada as análises para a participação das empresas desse porte no total de empresas inovadoras com apoio (indicador ICAP na tabela 1). Já as grandes empresas concentram principalmente incentivos fiscais, porém para estas, esse tipo de apoio está relacionado principalmente com inovações em produtos para o mercado nacional, enquanto para as médias empresas esse tipo de apoio é mais importante para inovações em termos mundiais. Ou seja, os incentivos fiscais podem estar sendo mais efetivo para inovações mais incertas nas empresas médias do que nas empresas grandes. Isso pode ser explicado pela elevada presença de filiais de multinacionais dentre as grandes empresas brasileiras que acessam incentivos fiscais uma vez que as multinacionais tendem a desenvolver seus produtos na sua matriz, limitando o número de grandes empresas que geram, no Brasil, inovações novas para mundo.

Porém, vale salientar que as grandes empresas tendem a buscar apoio em mais fontes do que as demais empresas. A título de ilustração, quando soma-se a parcela de empresas grandes com determinado apoio (Incentivo Fiscal, compra de Máquinas e Equipamentos, P\&D e Inovação, mais Subvenção), o total é de 129,8\%, enquanto para Média empresa, essa soma é de 109,2\% e, para pequenas empresas, 93,6\%. Ou seja, há indícios de que as grandes empresas se repetem em mais tipos de apoio do que os demais portes. A não observação dessa co-ocorrência entre os tipos de apoio é uma limitação do estudo, assim como a ausência de análises setoriais e da origem de capital. Ambas podem ser objetos de estudos futuros.

\section{Conclusão}

Em vista das características do processo inovativo, o financiamento à inovação, na maioria dos países, conta com recursos públicos e com a atuação do governo. O instrumento mais antigo, e amplamente utilizado em vários países, é o incentivo fiscal para as atividades de P\&D. Esta é uma etapa do processo de inovação, que envolve um elevado percentual de risco tecnológico, mas não é a única. Este instrumento, por isto, tende a favorecer as empresas já estabelecidas.

Por sua vez, os incentivos não fiscais visam cobrir algumas das demais etapas do processo de inovação - como estudos de viabilidade, desenvolvimento de protótipos, comercialização, dentre outras -, bem como dar o suporte necessário às MPEs e às empresas de base tecnológica. Estes incentivos, que podem se dar através do aporte direto de recursos nas empresas ou da participação no custo, exigem para o seu funcionamento a existência de instituições ou de agências específicas, bem como a seleção dos setores e projetos a serem contemplados.

No Brasil, os incentivos fiscais vêm sendo concedidos desde o início da década de 90, mas só conseguiram atingir um maior número de empresas após a "Lei do Bem”, implementada em 2005. Os incentivos não fiscais são concedidos principalmente pela FINEP e pelo BNDES, que vem fazendo um esforço crescente para adequar seus instrumentos às necessidades das empresas. Inclusive, o aumento no número de empresas beneficiárias de incentivos e de recursos financeiros nas diversas edições da PINTEC, principalmente a presença expressiva de pequenas e médias empresas, sugere um processo de aprendizado no uso dos mecanismos por parte das empresas.

Contudo, fica ainda a necessidade da prática do monitoramento dos resultados dos recursos aportados que ainda não é uma realidade destas instituições, não permitindo aprendizado interativo que possa alimentar as decisões sobre "projetos e áreas de interesse”. O presente artigo procurou contribuir neste sentido procurando articular o tipo do instrumento de apoio e o grau de novidade da inovação, na busca de inferir uma relativa “efetividade” do instrumento na promoção de inovações que tenham lidado com um maior nível de incerteza.

O quadro 3 sumariza a relação entre tipo de instrumento de apoio, porte das empresas e grau de novidade da inovação de produto, discutida ao longo do estudo.. 
Quadro 3 - Relação entre tipo de apoio, porte e grau de novidade da inovação de produto: hipóteses analisadas.

Tipo de apoio

Hipóteses (H)

H1

Incentivo Fiscal

Porte:

Grande

Grau de novidade:

Baixo

H1 não rejeitada?

Parcialmente

H2

Subvenção

Porte:

Indefinido

Grau de novidade:

Alto

H2 não rejeitada?

Sim

H3.1

Crédito para compra de $\mathrm{M} \& \mathrm{E}$

Porte:

Pequena

Grau de novidade:

Baixo

H3.1 não rejeitada?

Sim

H3.2

Crédito para P\&D e Inovação

Porte:

Grau de novidade:

Grande

H3.2 não rejeitada?

Alto

Sim

Fonte: Elaboração própria.

A hipótese 1 é parcialmente aceita pois os incentivos fiscais foram concentrados em grandes empresas em 2009-2011, mas estiveram atrelados a inovações novas para o mundo principalmente para médias empresas, enquanto para grandes empresas, o incentivo fiscal resultou de forma mais predominante em inovações novas para o país. Já a hipótese 2 não foi rejeitada pois a subvenção esteve associada com inovações para o mundo nas empresas de todos os portes e mostrou-se concentrada tanto em médias quanto em grandes empresas, apesar de ser o instrumento com menor quantidade de empresas apoiadas, em todos os portes analisados. Por fim, a terceira hipótese não foi rejeitada para o crédito para compra de máquinas e equipamentos, afinal, este esteve relacionado sempre com inovações apenas para a empresa e foi concentrada nas pequenas empresas. Porém, para o crédito a P\&D e Inovação, este foi concentrado em médias e grandes empresas, mas foi relevante principalmente para inovações para o país no caso das grandes empresas, ocupando sempre a segunda posição quanto à inovação para o mundo. Dessa forma, não se pode rejeitar a relação entre crédito para $\mathrm{P} \& \mathrm{D}$, grande empresa e inovações para o mundo.

Estes resultados indicam, pois, a importância da existência de distintos instrumentos no fomento à inovação para as empresas, principalmente, pela necessidade de lidar com as especificidades dos diferentes tamanhos de empresa, bem como com as distintas necessidades de recursos financeiros ao longo do processo de inovação. Como agenda de pesquisa futura seria importante uma análise que contemplasse a origem do capital das empresas, os diversos setores industrias, bem como que conseguisse analisar a empresa ao longo do tempo. Compreender a relação entre os tipos de instrumentos financeiros e grau de incerteza é importante para que o financiamento público possa cumprir um papel ainda mais importante no financiamento do processo de inovação 


\section{BIBLIOGRAFIA}

ARAUJO, B. Políticas de apoio à inovação no Brasil: uma análise de sua evolução recente. IPEA. Brasília, 2012 (Texto para discussão, 1759).

CAVALCANTE, L. Consenso difuso, dissenso confuso: paradoxos da política de inovação no Brasil. IPEA. Brasília, 2013 (Texto para discussão, 1867).

CORDER, S. Política de inovação tecnológica no Brasil: experiência recente e perspectivas. IPEA. Brasília, 2006 (Texto para discussão, 1244).

IBGE. Pesquisa de Inovação 2011. Rio de Janeiro: Instituto Brasileiro de Geografia e Estatística, 2013. Disponível em <http://www.pintec.ibge.gov.br/>. Acesso em 18 de jan. 2015.

MAZZUCATO, M. O Estado Empreendedor. São Paulo: Portfólio-Penguin, 2014.

MORAIS, J. Políticas de apoio financeiro à inovação tecnológica: avaliação dos programas MCT/Finep para empresas de pequeno porte. IPEA. Brasília, 2007 (Texto para discussão, 1296).

NASCIMENTO, P; OLIVEIRA, J. Redirecionamento, redistribuição, indução ou nenhuma das alternativas? Exame do papel das ações transversais no FNDCT entre 2004 e 2008. IPEA. Brasília, 2011 (Texto para discussão, 1664)..

PACHECO, C. A. As reformas da política nacional de ciência, tecnologia e inovação no Brasil (19992002). Manual de Políticas Públicas, Programa CEPAL-GTZ Modernización del Estado. Chile: CEPAL, 2007.

QUEIROZ, G.; CAVALCANTE, L. Evolução da execução orçamentária do Ministério da Ciência, Tecnologia e Inovação entre 2001 e 2010. IPEA. Brasília, 2012 (Texto para discussão, 1751).

RIO DE JANEIRO. FINEP. Relatório de Gestão do Exercício de 2014. Rio de Janeiro: Financiadora de Estudos e Projetos, 2015. Disponível em: <https://www.finep.gov.br/images/afinep/transparencia/relatorios/relatorios-de-gestao/2014/2015-06-

29_Relatorio_de_Gestao_FINEP_2014_RD-CF-CA-TCU.pdf>. Acesso em: 30 jan. 2016.

SALLES-FILHO, S.; STEFANUTO, G.;MATTOS, C.; ZEITOUM, C.CAMPOS, F.R. Avaliação de impactos da Lei de Informática: uma análise da política industrial e de incentivo à inovação no setor de TICs brasileiro. Revista Brasileira de Inovação, v. 11, p.191-128, julho, 2012.

TORRES, P.H.; BOTELHO, M. Interação Universidade-Empresa no Brasil: uma análise a partir de casos selecionados de empresas contempladas pelo PAPPE. Mimeo, 2016.

ZUCOLOTO, G. Origem do capital e acesso aos incentivos fiscais e financeiros à inovação no Brasil. IPEA. Brasília, 2012 (Texto para discussão, 1753). 


\section{ANEXOS}

Tabela A1 - Número de empresas inovadoras que receberam determinado tipo de apoio, de acordo com o porte e total (Gráficos 2 e 3 e Tabela 1).

\begin{tabular}{lrrrrrr}
\hline & \multicolumn{5}{c}{ Número de empresas Inovadoras (produto ou processo) } \\
\cline { 2 - 7 } & \multirow{2}{*}{ Total } & \multicolumn{5}{c}{ Receberam apoio } \\
\cline { 2 - 7 } & & \multicolumn{1}{c}{ Total } & Compra de M\&E & P\&D e Inovação & Incentivos fiscais & \multicolumn{1}{c}{ Subvenção } \\
\hline Pequena & 40572 & 13376 & 10568 & 876 & 824 & 258 \\
Média & 4129 & 1640 & 1014 & 193 & 468 & 115 \\
Grande & 1249 & 680 & 178 & 142 & 496 & 66 \\
\hline Total & 45950 & 15696 & 11760 & 1211 & 1787 & 439 \\
\hline
\end{tabular}

Fonte: PINTEC 2011 (IBGE, 2013). Elaboração Própria

Tabela A2 - Número de pequenas empresas inovadoras em produtos com determinado grau de novidade, por tipo de apoio recebido (Gráfico 4).

\begin{tabular}{|c|c|c|c|c|c|c|c|}
\hline & \multirow{2}{*}{$\begin{array}{c}\text { Total } \\
\mathrm{N}^{\mathrm{o}}\end{array}$} & \multicolumn{2}{|c|}{ Novo para empresa } & \multicolumn{2}{|c|}{ Novo para o mercado nacional } & \multicolumn{2}{|c|}{ Novo para o mundo } \\
\hline & & $\mathrm{N}^{0}$ & $\%$ & $\mathrm{~N}^{\mathrm{o}}$ & $\%$ & $\mathrm{~N}^{\mathrm{o}}$ & $\%$ \\
\hline Compra de $M \& E$ & 4950 & 4543 & 91.79 & 379 & 7.65 & 28 & 0.57 \\
\hline$P \& D$ e inovação & 625 & 364 & 58.28 & 234 & 37.41 & 27 & 4.31 \\
\hline Incentivos fiscais & 564 & 441 & 78.13 & 101 & 17.92 & 22 & 3.95 \\
\hline Subvenção & 204 & 89 & 43.65 & 88 & 43.29 & 27 & 13.06 \\
\hline
\end{tabular}

Fonte: PINTEC 2011 (IBGE, 2013). Elaboração Própria

Tabela A3 - Número de médias empresas inovadoras em produtos com determinado grau de novidade, por tipo de apoio recebido (Gráfico 5).

\begin{tabular}{|c|c|c|c|c|c|c|c|}
\hline & \multirow{2}{*}{$\begin{array}{c}\text { Total } \\
\mathrm{N}^{\circ}\end{array}$} & \multicolumn{2}{|c|}{ Novo para empresa } & \multicolumn{2}{|c|}{ Novo para o mercado nacional } & \multicolumn{2}{|c|}{ Novo para o mundo } \\
\hline & & $\mathrm{N}^{\mathrm{o}}$ & $\%$ & $\mathrm{~N}^{\mathrm{o}}$ & $\%$ & $\mathrm{~N}^{\mathrm{o}}$ & $\%$ \\
\hline Compra de M\&E & 504 & 397 & 78.87 & 84 & 16.58 & 23 & 4.55 \\
\hline P\&D e inovação & 147 & 79 & 53.79 & 50 & 34.13 & 18 & 12.08 \\
\hline Incentivos fiscais & 361 & 179 & 49.62 & 129 & 35.74 & 53 & 14.64 \\
\hline Subvenção & 66 & 29 & 44.28 & 27 & 40.99 & 10 & 14.74 \\
\hline
\end{tabular}

Fonte: PINTEC 2011 (IBGE, 2013). Elaboração Própria

Tabela A4 - Número de grandes empresas inovadoras em produtos com determinado grau de novidade, por tipo de apoio recebido (Gráfico 6).

\begin{tabular}{lccccccc}
\hline & $\begin{array}{c}\text { Total } \\
\mathrm{N}^{\mathrm{o}}\end{array}$ & \multicolumn{2}{c}{$\begin{array}{c}\text { Novo para empresa } \\
\mathrm{N}^{\mathrm{o}}\end{array}$} & $\%$ & $\begin{array}{c}\text { Novo para o mercado nacional } \\
\%\end{array}$ & $\begin{array}{c}\text { Novo para o mundo } \\
\mathrm{N}^{\mathrm{o}}\end{array}$ & $\begin{array}{c}\text { \% } \\
\%\end{array}$ \\
\hline Compra de M\&E & 127 & 70 & 54.96 & 43 & 33.80 & 14 & 11.25 \\
P\&D e inovação & 125 & 44 & 34.74 & 50 & 39.72 & 32 & 25.53 \\
Incentivos fiscais & 434 & 188 & 43.40 & 165 & 37.99 & 81 & 18.60 \\
Subvenção & 63 & 22 & 34.45 & 22 & 35.25 & 19 & 30.30 \\
\hline
\end{tabular}

Fonte: PINTEC 2011 (IBGE, 2013). Elaboração Própria 